\title{
Memory Drugs and cAMP-Response Element Binding Protein
}

\author{
Özge Çoşkun (1)
}

\section{CAMP-response element binding protein (CREB) Activation}

CREB is involved in many different signal pathways. In order to be functional in these pathways, it needs to be phosphorylated. This phosphorylation is mainly made by kinases, but studies have shown that increased amount of calcium $(\mathrm{Ca})$ in the nucleus in nerve cells can also activate CREB. ${ }^{[1]}$

\section{PROTEIN SYNTHESIS AND MEMORY}

Long-term studies have shown that protein synthesis is a key step in the processing of longterm memory. ${ }^{[2]}$ In one of the experiments, the use of an antibiotic (puromycin), which inhibits protein synthesis on the mouse, adversely affected long-term memory formation, and protein synthesis has been one of the points studied with memory for years. However, the complexity of the system and the side effects of the chemicals used in the experiments on the nerves and memory are among the factors that make it difficult to work and to reach a conclusion. ${ }^{[3]}$

Another point observed in the experiments is that the given long term memory inhibitory chemicals do not have any inhibitory effect on the function of short term memory. ${ }^{[4]}$

Istanbul Aydın University Medical School, Istanbul, Turkey

Correspondence: Özge Çoşkun. Aydın Üniversitesi Tıp Fakültesi, 34295 Küçükçekmece, İstanbul, Türkiye.

E-mail: coskunozge98@gmail.com

Cite this article as: Çoşkun Ö. Memory Drugs and CAMP-Response Element Binding Protein. JEB Med Sci 2020;1(2):82-85.

doi: $10.5606 /$ jebms.2020.75618

Received : February 19, 2019

Accepted : January 15, 2020

Published online : November 09, 2020

(๑)2020 Journal of Experimental and Basic Medical Sciences. All rights reserved.

\begin{abstract}
CAMP responsive binding protein (CREB) is a transcription factor (CREB/ATF) that binds to the promoter of the CAMP responsive element and is a member of a very large family. CREB is the first isolated member of this family, but currently has at least 10 members. This protein family shows very different variations, is synthesized in many different cells and tissues and acts as signaling pathways in many different pathways. In this review, we will examine the effects of CREB and CREB-dependent chemicals on memory.

Keywords: Mice, protein, puromycin, transcription factor.
\end{abstract}

\section{LONG AND SHORT TERM MEMORY AND CREB, MEMORY AND NEUROPLASTICITY}

Memory is basically stored in the hippocampus of the brain. The CA1 region of the hippocampus stores the newly learned datas in memory, while CA3 provides long-term memory. They use many different transcription factors during these processes. The most studied transcription factor is CREB. However, studies are still on going and the functions of the hippocampus sections have not been completely clarified yet..$^{[5]}$

CREB is a necessary and essential transcription factor in long-term memory formation. It is a molecular converter that converts short-term memory into long-term memory. Loss of function of the CREB molecule also damages the memory ${ }^{[6,7]}$ In this case, an inhibitor of CREB also prevents the formation of long-term memory .The stimuli that activate CREB facilitate memory formation. ${ }^{[8]}$

Studies on CREB started with Aplysia Californica, a sea mollusk, and continued with a fruit fly, Drosophila. Recent studies have focused on mice and no experiments have been performed on human cells yet. ${ }^{[8]}$ 


\section{Aplysia Californica}

In the experiments performed on Aplysia Californica, animals were divided into different groups and the gills of each group were given different values of electric current for different durations. They developed with drawal reflexes in order to protect themselves from the electrical current that changed the behavior of animals as a result of the given currents. At the end of the experiment, it was observed the number of synapses between sensory and motor neurons and the stimulation of nerve cells increased in response to the given signals. The shortterm memory caused by the short-term stimulation, the increase in the duration of stimulation, increased expression of C/EBP, and consequently the number of synapses increased, short term memory converts into long-term memory. ${ }^{[9,10]}$

\section{NEURODEGENERATIVE DISEASES, CREB AND MEMORY}

The brain is a kind of machine that manages memory, our behavior, our social functions, our motor functions, and our entire body, whether we realize it or not. Therefore, when this complex machine is damaged, its functions are disrupted and diseases occur. ${ }^{[11]}$

Neurodegenerative diseases are progressive diseases due to the damage and loss of nerve cells and progressively progress with loss of cognitive, sensory and motor functions. Diseases such as Alzheimer's Disease and Parkinson's Disease, which we often come across in daily life, are examples of neurodegenerative diseases. Alzheimer's Disease is characterized by the formation of intracellular neurofibrillary nodes, which are caused by excessive phosphorylation of the tau protein, which is the cause and formation of amyloid beta plaques. ${ }^{[1]]}$ Parkinson's disease is associated with the loss of dopaminergic receptors in the substancia nigra. ${ }^{[12]}$ According to statistical estimates, cases of neurodegenerative disease are expected to be $11-14 \%$ by 2020 . According to the Alzheimer's Association data, an Alzheimer's diagnosis is made every 65 seconds in the United States, and 6.5 million people live with the diagnosis of Alzheimer's. Scientists are researching to find treatment for these diseases. ${ }^{[13]}$

According to studies, decreased CREB levels or insufficient CREB function or CREB activation cause memory loss and Alzheimer's Disease. The obviation of this CREB deficiency with memory medications has been a new hope for the treatment of memory disorders, particularly Alzheimer's. ${ }^{[5]}$

Studies on amnesic mice show that a chemical called Bacoside activates CREB kinases, are CREBactivating molecules and CREB-dependent molecules in hippocampus and brain cortex neurons and facilitates neuroplasticity. ${ }^{[14-16]}$ Show that bacoside inhibits acetylcholine esterase, which is thought to cause Alzheimer's Disease, which digests acetyl choline and is the cause of low levels of acetyl choline. ${ }^{[17,18]}$

\section{STRENGTHENING MEMORY WITH REINFORCEMENTS}

In the light of the informations about memory formation, memory enhancers that regulate neurotransmitters, hormones and regulating metabolizers are designed for the treatment of diseases related to memory loss. ${ }^{[19]}$

\section{Memory Enhancing Supplements Using CAMP-CREB-C / EBP Pathway Molecular}

Research has shown that gene expression due to CAMP, CAMP product CREB and C-EBP in the spinal cord is a key step in long-term memory formation and neuroplasticity. ${ }^{[20,21]}$ Studies show that loss of memory is a result to damage CREB and C/EBP molecules. ${ }^{[19]}$ In contrast, over-expression of CAMP and its products has been shown to increase long-term memory and neuroplasticity. ${ }^{[22]}$ In this case, stimulation of the expression of CREB and C / EBP will strengthen the memory. ${ }^{[23]}$

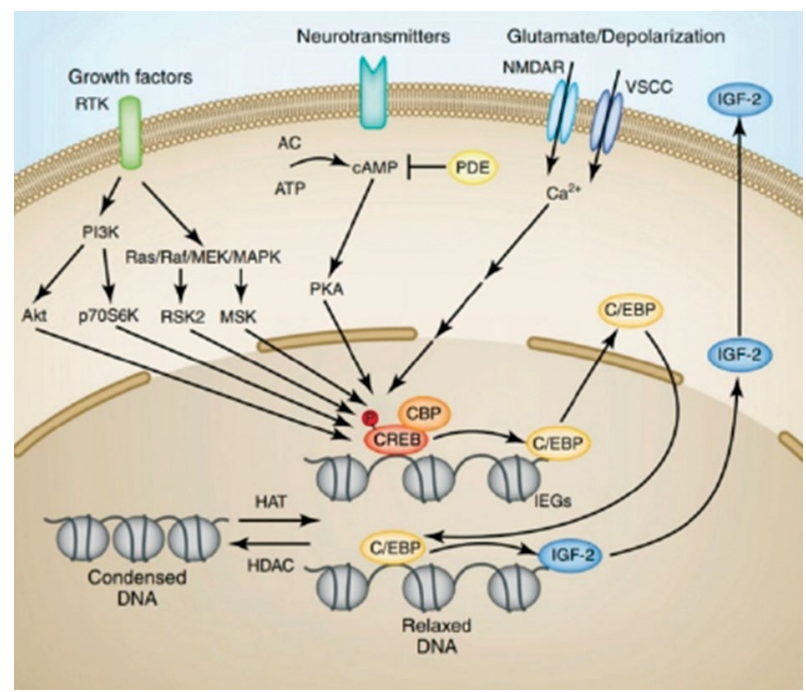

Figure 1. CAMP-response element binding protein and memory mechanism. ${ }^{[23]}$ 
So how does CREB do it? Studies show that CREB acts on chromatin and controls whether transcription proteins can reach DNA. Thus, it regulates the synthesis of protein are required for memory formation and manages the memory formation process (Figure 1). ${ }^{[23]}$

\section{Insulin-like Growth Factor 2 (IGF2)}

IGF2 is an important polypeptide in normal growth, development and tissue repair. It was found in brain tissue, especially in the hippocampus and cortex where memory is preserved compared to other members of the family of which it is a member. Although the function of IGF2 has not been completely clarified yet, it is known that it has many different signalling roles within the cell. ${ }^{[24]}$

Experiments on mice, which research the relationship between IGF2 and memory, show that: injecting recombinant IGF2 into the hippocampus within the first 24 hours after the mouse has been trained, had helped to process long-term memory. ${ }^{[25]}$

\section{Declaration of conflicting interests}

The authors declared no conflicts of interest with respect to the authorship and/or publication of this article.

\section{Funding}

The authors received no financial support for the research and/or authorship of this article.

\section{REFERENCES}

1. Hardingham GE, Chawla S, Johnson CM, Bading H. Distinct functions of nuclear and cytoplasmic calcium in the control of gene expression. Nature 1997;385:260-5.

2. Barondes SH. Protein synthesis dependent and protein synthesis independent memory storage processes. In: Deutsch D, Deutsch JA, editors. Short-Term Memory. New York: Academic; 1975. p. 379-90.

3. Flexner JB, Flexner LB, Stellar E. Memory in mice as affected by intracerebral puromycin. Science 1963;141:57-9.

4. Goyal K, Konar A, Kumar BSH, Koul V. Lactoferrinconjugated $\mathrm{pH}$ and redox-sensitive polymersomes based on PEG-S-S-PLA-PCL-OH boost delivery of bacosides to the brain. Nanoscale 2018;10:17781-98.

5. Bianchi D, De Michele P, Marchetti C, Tirozzi B, Cuomo $\mathrm{S}$, Marie $\mathrm{H}$, et al. Effects of increasing CREB-dependent transcription on the storage and recall processes in a hippocampal CA1 microcircuit. Hippocampus 2014;24:165-77.

6. Ortega-Martínez S. A new perspective on the role of the CREB family of transcription factors in memory consolidation via adult hippocampal neurogenesis. Front Mol Neurosci 2015;8:46.

7. Ricciarelli R, Fedele E. cAMP, cGMP and Amyloid $\beta$ : Three Ideal Partners for Memory Formation. Trends Neurosci 2018;41:255-66.
8. Miller-Fleming L, Olin-Sandoval V, Campbell K, Ralser M. Remaining Mysteries of Molecular Biology: The Role of Polyamines in the Cell. J Mol Biol 2015;427:3389-406.

9. Lee JA, Kim HK, Kim KH, Han JH, Lee YS, Lim CS, et al. Overexpression of and RNA interference with the CCAAT enhancer-binding protein on long-term facilitation of Aplysia sensory to motor synapses. Learn Mem 2001;8:220-6.

10. Frost WN, Castellucci VF, Hawkins RD, Kandel ER. Monosynaptic connections made by the sensory neurons of the gill- and siphon-withdrawal reflex in Aplysia participate in the storage of long-term memory for sensitization. Proc Natl Acad Sci U S A 1985;82:8266-9.

11. Tanifum EA, Dasgupta I, Srivastava M, Bhavane RC, Sun $\mathrm{L}$, Berridge J, et al. Intravenous delivery of targeted liposomes to amyloid- $\beta$ pathology in APP/PSEN1 transgenic mice. PLoS One 2012;7:e48515.

12. Bartus RT, Weinberg MS, Samulski RJ. Parkinson's disease gene therapy: success by design meets failure by efficacy. Mol Ther 2014;22:487-97.

13. Available at: https://www.alz.org/media/HomeOffice/ Facts\%20and\%20Figures/facts-and-figures.pdf

14. Preethi J, Singh HK, Charles PD, Rajan KE. Participation of microRNA 124-CREB pathway: a parallel memory enhancing mechanism of standardised extract of Bacopa monniera (BESEB CDRI-08). Neurochem Res 2012;37:2167-77.

15. Pandareesh MD, Anand T, Khanum F. Cognition Enhancing and Neuromodulatory Propensity of Bacopa monniera Extract Against Scopolamine Induced Cognitive Impairments in Rat Hippocampus. Neurochem Res 2016;41:985-99.

16. Konar A, Gautam A, Thakur MK. Bacopa monniera (CDRI08) Upregulates the Expression of Neuronal and Glial Plasticity Markers in the Brain of Scopolamine Induced Amnesic Mice. Evid Based Complement Alternat Med 2015;2015:837012.

17. Ramasamy S, Chin SP, Sukumaran SD, Buckle MJ, Kiew LV, Chung LY. In Silico and In Vitro Analysis of Bacoside A Aglycones and Its Derivatives as the Constituents Responsible for the Cognitive Effects of Bacopa monnieri. PLoS One 2015;10:e0126565.

18. Mishra A, Mishra AK, Jha S. Effect of traditional medicine brahmi vati and bacoside A-rich fraction of Bacopa monnieri on acute pentylenetetrzole-induced seizures, amphetamine-induced model of schizophrenia, and scopolamine-induced memory loss in laboratory animals. Epilepsy Behav 2018;80:144-51.

19. Alberini $\mathrm{CM}$. Transcription factors in long-term memory and synaptic plasticity. Physiol Rev 2009;89:121-45.

20. Alberini $C M$, Ghirardi $M$, Metz R, Kandel ER. C/EBP is an immediate-early gene required for the consolidation of long-term facilitation in Aplysia. Cell 1994;76:1099-114.

21. Tully T, Preat T, Boynton SC, Del Vecchio M. Genetic dissection of consolidated memory in Drosophila. Cell 1994;79:35-47.

22. Lee JA, Kim HK, Kim KH, Han JH, Lee YS, Lim CS, et al. Overexpression of and RNA interference with 
the CCAAT enhancer-binding protein on long-term facilitation of Aplysia sensory to motor synapses. Learn Mem 2001;8:220-6.

23. Alberini CM, Chen DY. Memory enhancement: consolidation, reconsolidation and insulin-like growth factor 2. Trends Neurosci 2012;35:274-83.

24. Rotwein P, Burgess SK, Milbrandt JD, Krause JE.
Differential expression of insulin-like growth factor genes in rat central nervous system. Proc Natl Acad Sci U S A 1988;85:265-9.

25. Chen DY, Stern SA, Garcia-Osta A, Saunier-Rebori B, Pollonini G, Bambah-Mukku D, et al. A critical role for IGF-II in memory consolidation and enhancement. Nature. 2011;469:491-7. 